\title{
Factors Analysis of the Adoption of Cloud Computing in England
}

\author{
Raja Muhammad Ubaid Ullah ${ }^{\# 1}$, Dr.Kevan A. Buckley ${ }^{\# 2}$,Dr. Mary Garvey ${ }^{\# 3}$, Dr. Jun Li ${ }^{\# 4}$. \\ School of Mathematics and Computer Science \\ University of Wolverhampton, Wulfruna Street, Wolverhampton WVI ILY, UK.
}

\begin{abstract}
The trend in information technology has been changed by cloud computing (CC) services to facilitate the day to day business activities. CC services benefits for business and information technology (IT) includes a secure platform, reducing cost and increasing productivity. There are some challenges for some organisations that adopting CC services without ensuring that the information in the cloud is secure. The primary objective of this research is to investigate the IT and IT professional perception regarding the adoption of CC services as a new generation trend in computing technology. However, the extent of CC adoption services, to identify some of the factors motivating and some challenges affecting the adoption of CC services in England. Still some organisations are struggling, how to create a secure and cost effective CC services environment.The expected finding from this research believe to provide the certain analysis and confirm the significant factors from which perceptions are derived through classification, that can address the business and technology related issues by CC services. Especially, in this study, the CC users analyse the secure platform technologies, compatibility, cost evaluation and some other types of control they assume are beneficial for the deployment of on-premise or in the cloud environment. The interview data are presented, where CC services users reviews are collected to rate the different types of important information's related to CC services adoption. Then results are used to determine the compatibility, security and cost effectiveness are critical parameter to make this technology as a turning point for the organisation for their day to day business activities.
\end{abstract}

Keywords - cloud, computing, technology, IT, adoption, affecting

\section{INTRODUCTION}

Many challenges are faced by organisations and businesses according to their size and structure. Access to enough resources is not the main challenge (e.g. financial resources). Furthermore, in evaluation to large companies, small firms have less cost tolerance and risk of adopting new innovations. Businesses and organisations are very cost conscious; their main objective is to keep costs under control. While new technologies adoption help businesses and organisations gain competitive advantage, sometimes it involves usually high cost. Any IT investment comprises different types of costs such as fixed costs, operation costs and training costs. In some cases, the actual cost of the project goes higher than the initial estimate [1,27]. High costs and risks that are elaborated in IT projects, prevent businesses and organisations to easily invest in new technologies adoption.

The phenomenon of CC helps businesses and organisations tackling many issues such as cost and risk management $[2,28]$. CC has no universal definition; whereas, in this research,CC is defined as a computing standard in which the computing resources are distributed to different customers over a network (e.g. Internet). The access of computing resources for companies available by services ondemand, through the network (e.g. Internet) at anytime and anywhere [6]. CC provides an alternative of installing applications and systems on-premises. Where customers do not need to install or develop in-house computing resources. Computing resources, which are not restricted to networks, servers, storage, applications, and services can be accessed over a network (e.g. Internet) by customers. The primary differences between on-premises developing system and using $\mathrm{CC}$ are that the operation of actual technology is not the responsibility of customers. They only use computing resources and pay for the used services. This considerably reduces the risk and managing the technology cost, which is specifically beneficial to businesses and organisations. CC helps businesses and organisations to significantly reduce the investment cost, project risk, operation and maintenance costs $[1,27,28]$.

Another difference between traditional computing (i.e. developing in-house systems) and CC is the payment model of cloud computing. The pay-asyou-go payment model allows companies to only 
pay for the service that they have used. The access of most sophisticated computing services used by companies, without investing any money in advance. Companies do not need to pay upfront for buying, installing or licensing the system. Furthermore, maintaining and upgrading hardware and software applications is not the responsibility of companies. Although there are many advantages of CC for companies, there are some drawbacks related to this new phenomenon. Some other researchers discussed the issues related to the cloud's security, reliability, availability, etc. Whereas, some legal concerns about the ownership of the data and the location of the data centre's where data are saved. While signing a comprehensive Service-Level-Agreement (SLA) [3] majority of these concerns and issues can be carefully considered by companies.

The essential features of $\mathrm{CC}$ is a unique combination of capabilities which are:

- Scalable and dynamic infrastructure,

- Global/Remote access,

- Précised usage controls and pricing,

- Standard Platform, and

- $\quad$ Support Services - IT and Management.

The new strategy will allow companies to incorporate the latest technologies, reduce in costs, develop process innovation and boost their speed of business activities. Based on the new technologies a developed IT infrastructure can remove some of the barriers of global market competition and permit companies to be more efficient, competitive and also offer a degree of flexibility. The potential of $\mathrm{CC}$ to play a primary role in addressing inefficiencies and make an essential involvement in the growth and competitiveness of companies [4]. $\mathrm{CC}$ technology offers a new path to business agility and faster market time support by offering ready-to consume cloud supporting resources such as IT infrastructure as a service, software platforms, and business applications.

\section{CHALLENGES OF CLOUD COMPUTING ADOPTION}

However, there are several benefits of $\mathrm{CC}$, there are numerous challenges that need to be addressed before it can be recognized as a feasible ICT choice for the organizations [5]. There are many challenges related to $\mathrm{CC}$ adoption. According to a different survey conducted by the companies, the three most reported challenges of cloud services are security, availability, and performance [9]. Some researchers also highlighted other challenges which may affect an organization's decision to adopt cloud computing. There are widely common reported challenges are mentioned below.

\section{A. Security and Confidentiality}

These are the highest reported and fundamental issues which prevent customers from adopting cloud technology [15]. The applications and data of the customers are vulnerable to a different level of security threats like data loss and unauthorized access, which result in a lack of control over cloud data and infrastructure [7]. Although the cloud service provider (CSP) give assurance to customers that they use professional experts to manage their data centres, but the customers still have a concern about who is monitoring and managing their confidential data. Therefore, to ensure data confidentiality, the following techniques are applied to overcome the security and privacy challenges:

- Encryption:During data transfer and storage in the cloud, encryption is used as the main method to protect it. The authenticity and integrity of the data are to ensure and prevent it from improper disclosure of confidential data. Usually, organizations prefer handling the encryption by themselves to enhance the confidentiality of their valuable data [7].

- Digital signature: The digital signature method authenticates the identity of the user that requires appropriate login to a procedure to access the data [16].

- Identification and authentication: The access is controlled by cloud services so that only validated user should get through. Therefore, different accounts for employees according to their job title should be created and validated using username and passwords. The process of verification should be strongly implemented so that a customer's data is not compromised [17].

- Authorisation: The access of every user is based on their privilege using priorities, permissions and ownership. This will ensure that "referential integrity is maintained" [17].

- Integrity and confidentiality: Any sort of sensitive and confidential business data should be protected by using encryption techniques. It also ensures the reliability of the data, which involves imposing Atomicity, Consistency, Isolation, and Durability properties on the cloud delivery models [17].

- Non-repudiation: To ensures that every end of electronic transactions is not denied. The 
timestamp, digital signature techniques and the digital receipt can be used for the confirmation of sending and receiving of data [17].

- Direct contact with the service provider: The enterprise must create direct contact with the CSP to reduce the data compromise chance by a third party.

- Gradual sequence of migration: The cloud moving process must be in stages starting with applications of insignificant risks. Which will ensure that the enterprise is satisfied with the provider before migrating sensitive and confidential data?

- Investigating the vendor: This ensures the checking of security measures to ensure that they are in defined lines with bodies like NIST and Cloud Security Alliance.

- Data splitting: This technique allows more than one cloud provider to store data for different purposes. For instance, enterprise email service is outsourced to Google and file storage service outsourced to Amazon. This type of technique improves confidentiality, availability, and integrity of the data, performance, avoid vendor lock-in and reduce risk of data loss and downtime.

\section{B. Availability}

The second most significant issue is availability which affects CC adoption. This factor is determined by reliability, latency and performance. Whereas, the issue of availability is common with cloud, as the infrastructure of most cloud is built to provide high availability. The availability ensuring cloud service or resource implies that the request of a customer is granted instantly, and the requested service is delivered immediately [8]. A steady and good quality internet connection will eliminate service outage that increases the availability and accessibility of the services. The high service availability to customers is guaranteed by the provider. The availability guarantee of cloud services is in SLA documents. Therefore, the availability considers the most significant issues when choosing between the types of cloud service and their delivery models [17].

\section{Performance}

The third most significant issue to be considered is a performance, which affects $\mathrm{CC}$ adoption. It is usually determined by the application's capabilities running on the cloud [10]. Sometimes distance factor also affects the performance of a cloud system between the cloud and the customer, because of delay. Internet is the source through which cloud services are delivered, so the cloud services performance depends on the Internet [9]. During the transmission process, the cloud data passes through different shared routes, hops and packets, where the data may be lost or corrupted. Therefore, the procedure could be adversely affected by data transmission challenges like delay and jitter which will subsequently result in poor performance.

The performance of reliability is also based on the Internet itself. The cloud service performance is significantly affected by a slow Internet connection. Therefore, a fast and reliable Internet connection is required for efficient service delivery [18]. The poor performance is experienced by organizations when cloud applications become unresponsive which result due to communication delay. The performance could be worse if multiple users are simultaneously using data-intensive services on a low bandwidth network. The serious consequence of poor performance results in the loss of customers which means a reduction in revenues. Hence, the provider should guarantee performance especially when it requires extensive computing power and timely availability of resources and search results.

\section{Costing Model}

The infrastructure cost can be reduced by cloud computing, but due to the high use of network resources such as data usage and bandwidth, will increase the data communication cost [20]. The higher cost of computing resources relates to more use of resources for data exchange between providers and organizations. The cloud pricing models include pay-as-you-go and subscription pricing. The user must consider the costing model of a provider and the resulted trade-offs should be carefully analysed prior to deployment [7]. This will help to weigh the benefits against the cost with respect to maximizing the benefits over the cost of considering the desired level of security. A limited budget for organizations to use pay-as-you-go plan [19], while subscription pricing is the best where there are long term and well-defined requirements. Therefore, using hybrid cloud result in a better return on investment [7].

\section{E. Compliance and Physical Location}

Compliance is the main factor in the adoption of $\mathrm{CC}$ because the location of data is not known by the customer or may not have control over the location, which creates legal issues with regulatory and privacy laws [19, 21]. Many European Union countries and the USA do not give permission to a certain type of data to be moved out of their countries. Such as, customers who have their cloud 
data stored in the USA should comply with rules concerning storage and disclosure of data. The other aspect is legal issues that can bind institutions into unsatisfactory conditions which may result in legal disputes due to laws of the data stored location.

\section{F. Service Level Agreement (SLA)}

The contract between CSP and customer is referred to SLA, which clearly specifies what services the provider will offer and up to what level. SLA is documentary evidence, which guarantees efficient delivery of cloud services and resources by the provider. Such as ensuring the quality, availability, reliability, and performance of the services [20,7]. SLA is regarded as one of the crucial considerations while choosing the right cloud deployment model. At the time of contract customers usually, negotiate on SLAs with the providers to ensure service delivery feature meets their expectations [7].

\section{PRIMARY DATA COLLECTION METHDOLOGY}

\section{A. Interview}

For the collection of data, the face-to-face interview methodology was used it gives better interaction between interviewer and interviewee and also helps to make better observations. The interview method has the ability to produce a means wealth of broad narration of the research topic and also help to clear the air of any sort of ambiguity with respect to the responses of participants. Before conducting interview randomly selected companies within west midlands, England, been contacted through phone, explaining to them the aim of study and appointment is scheduled after their confirmation. The close-ended questionnaire was used in the interview and invite them to give their own professional views and comments. 17 experts from different size and sectors of the organisation were interviewed in IT as well as CC sectors and an average of a one-hour session with each individual.

\section{DATA ANALYSIS.}

\section{A. Respondents.}

Table 1 and 2 shows a summary of cloud and IT job experience results of respondents in England. The aim of the interview was to investigate the indepth view from the IT professional, IT expert's users, from different types of organisations in IT sector that allow the study aims to access and explore the knowledge of IT experts in the organisations. 17 IT professional contributed to the interview with a different organisational background. All the selected respondents have cloud and IT experience respectively the interview results reflect that the respondent minimum cloud experience is three years and the maximum is eight years. On the other hand, the overall IT experience of the respondents reflects that minimum experience is eight years and a maximum of nineteen years of job experience.

The respondent yearly cloud experience summary shows in Table 1. The respondents experience in cloud is shown in two categories; $0-4$ and 5-8 years. The respondent with $5-8$ years of experience in the field of the cloud is top of table $12(70.59 \%)$. Whereas, the respondent with $0-4$ years of experience in the field of the cloud are 5 (29.41\%). The statistics revealed that respondents generally have decent years of experience in the field of the cloud those been interviewed, this shows the evaluation of the factor by the respondent has the validity of the results.

Table 1: Respondents by Cloud Experience Year Wise Summary.

\begin{tabular}{|c|c|c|}
\hline Cloud Experience in Years & $\begin{array}{c}\text { Experience in No. } \\
\text { of Years }\end{array}$ & $\%$ \\
\hline 0 - 4 Year Exp. & 5 & $29.41 \%$ \\
\hline $5-8$ Year Exp. & 12 & $70.59 \%$ \\
\hline Total --> & 17 & $100.00 \%$ \\
\hline
\end{tabular}

The respondent's yearly overall IT job experience summary shows in Table 2. The IT field experience of the respondents is shown in two categories; 0-10 and 11-20 years. The respondent with $11-20$ years of experience in the field of the IT is top of table 13 $(76.47 \%)$. Whereas, the respondent with $0-10$ years of experience in the field of the IT are 4 $(23.53 \%)$.

The statistics revealed that respondents generally have decent years of experience in the field of the IT also those been interviewed, this shows the evaluation of the factor by the respondent has the validity of the results.

Table 2: Participantsby Job Experience Year Wise Summary.

\begin{tabular}{|c|c|c|}
\hline IT Job Experience in Years & $\begin{array}{l}\text { Experience in } \\
\text { No. of Years }\end{array}$ & $\%$ \\
\hline 0 - 10 Year Exp. & 4 & $23.53 \%$ \\
\hline 11-20 Year Exp. & 13 & $76.47 \%$ \\
\hline Total --> & 17 & $100.00 \%$ \\
\hline
\end{tabular}




\section{B. Participants by their job title.}

Table 3 reflects the 17 participants been interviewed are representing different types and size of the organisations. IT Manager is top of the table with $4(23.53 \%)$, at second position on the table the System Analyst and System Solution Manager contributed with $2(11.76 \%)$ each one participated respectively. Whereas, Client Support Engineer, Client Support Manager, IT Consultant, IT Coordinator, IT Support Manager, Manager Implementation, Oracle DBA, Software Engineer and System Support Manager contributed with 1 $(5.88 \%)$ each one participated respectively.

Participation of the respondent reflects from the executive, middle-level management and technical staff from different types, size and sectors of the organisations. Whereas, a noticeable percentage of the participant participated, for instance, decision makers, middle management and technical staff from different types, size and sectors of the organisations and how they are keen about the CC services. Statistics revealed that $\mathrm{CC}$ is still an ongoing new technology and more organisations are using or considering to use the CC services. The participant's feedback shows their concerns, interest and reliability on $\mathrm{CC}$ services and cloud technology still have a future in the businesses environment.

Table 3: Participantsby job title.

\begin{tabular}{|c|c|c|}
\hline Designations & $\begin{array}{c}\text { No. of } \\
\text { Respondents }\end{array}$ & $\%$ \\
\hline IT Manager & 4 & $23.53 \%$ \\
\hline System Analyst & 2 & $11.76 \%$ \\
\hline $\begin{array}{l}\text { System Solution } \\
\text { Manager }\end{array}$ & 2 & $11.76 \%$ \\
\hline $\begin{array}{l}\text { Client Support } \\
\text { Engineer }\end{array}$ & 1 & $5.88 \%$ \\
\hline $\begin{array}{l}\text { Client Support } \\
\text { Manager }\end{array}$ & 1 & $5.88 \%$ \\
\hline IT Consultant & 1 & $5.88 \%$ \\
\hline IT Coordinator & 1 & $5.88 \%$ \\
\hline IT Support Manager & 1 & $5.88 \%$ \\
\hline $\begin{array}{l}\text { Manager } \\
\text { Implementation }\end{array}$ & 1 & $5.88 \%$ \\
\hline Oracle DBA & 1 & $5.88 \%$ \\
\hline Software Engineer & 1 & $5.88 \%$ \\
\hline $\begin{array}{l}\text { System Support } \\
\text { Manager }\end{array}$ & 1 & $5.88 \%$ \\
\hline Total --> & 17 & $100.00 \%$ \\
\hline
\end{tabular}

\section{Company Status about CC Services Usage.}

Statistics revealed in Table 4 that the organisations who already adopted some cloud services 16 $(94.12 \%)$ are top of the table. Very low percentage in second position are those who are in the processes of implementing $1(5.88 \%)$. The majority numbers number of participation from those who already using some cloud services, which reveal that participant involvement is significant.

Table 4: Company Status about CC Services Usage.

\begin{tabular}{|l|c|c|}
\hline \multicolumn{1}{|c|}{ Company Status } & $\%$ & No. \\
\hline $\begin{array}{l}\text { We have already adopted } \\
\text { some cloud services }\end{array}$ & $94.12 \%$ & 16 \\
\hline $\begin{array}{l}\text { Are in the processes of } \\
\text { Implementing }\end{array}$ & $5.88 \%$ & 1 \\
\hline $\begin{array}{l}\text { We don't intend to adopt } \\
\text { any cloud services in near } \\
\text { future }\end{array}$ & $0.00 \%$ & 0 \\
\hline Other (please specify) & $0.00 \%$ & 0 \\
\hline
\end{tabular}

\section{Scope of Respondents Organisation.}

Interestingly the majority of the national level organisation participated from different types and sectors of the businesses environment. At the top position, the national level of organisations participated with $13(76.47 \%)$. In the second position, multinational level of organisations are participating with 4 (23.53). Statistic clearly revealed that more SMEs organisations are considered the CC services as compared to the multinational organisation.

Table 5: Scope of Organisations.

\begin{tabular}{|c|c|c|}
\hline $\begin{array}{c}\text { Organisation } \\
\text { Scope }\end{array}$ & $\begin{array}{c}\text { No. of } \\
\text { Organisations }\end{array}$ & $\%$ \\
\hline National & 13 & $76.47 \%$ \\
\hline Multinational & 4 & $23.53 \%$ \\
\hline Total $\rightarrow$ & 107 & $100 \%$ \\
\hline
\end{tabular}

\section{E. Respondents Organisation size.}

The acceptance indicator sometimes established on the size of the organisation for the adoption of any new technology. The statistical data collected through interview with respect to respondent's organisation size. The employee's strength of different sizes of the organisation is divided into four categories; less than 20, $20-100,100-1000$ and above than 1000. An overall of 17 responses collected in which top of the table is $20-100$ with $9(52.94 \%)$ response. In the second position, is $10-$ 1000 with $6(35.29 \%)$ response. Finally, the categories above than 1000 and less than 20 are 1 $(5.88 \%)$ each response respectively. 
The statistical data revealed that small and medium (SMEs) size organisations with decent numbers. Whereas, a large and very small organisation with less than 20 employees are very low in number. Encouraging factor is that different types of businesses either SMEs or large organisation still benefitted with this new technology. The results also show that SMEs are more beneficial due to cost factors and using the latest technology at a low cost to stay in a competitive environment. However, other factors for more using the CC services is the lack of resources to build their own in-house IT services infrastructure. But, up to a certain extent the large organisation also enjoying the benefits of CC services for their day to day business activities. The benefits of the new technology utilisation are not established with the size or sector of any organisation, the right decision on right time from the decision maker gives new energy to the organisation to make growth.

Table 6: Staff Employed by Respondent Organisations.

\begin{tabular}{|l|c|c|}
\hline $\begin{array}{c}\text { No of } \\
\text { Employee's } \\
\text { Category }\end{array}$ & $\begin{array}{c}\text { No. of } \\
\text { Responses }\end{array}$ & Percentage \\
\hline $20-100$ & 9 & $52.94 \%$ \\
\hline $100-1000$ & 6 & $35.29 \%$ \\
\hline $\begin{array}{l}\text { Above than } \\
1000\end{array}$ & 1 & $5.88 \%$ \\
\hline Less than 20 & 1 & $5.88 \%$ \\
\hline Total $\rightarrow$ & 17 & $100.00 \%$ \\
\hline
\end{tabular}

\section{F. Relative Advantage}

Relative advantage is defined as "the degree to which an innovation is perceived as being better than the idea it supersedes" $[22,14]$. According to [21] organisations recognize the significant importance of relative advantages of cloud computing, such as in reducing IT costs, creating a competitive advantage, and enabling easier access to the information. In this research, the concept of relative advantage is used as the degree to which understand CC technology as being better than other computing paradigms. The organisation needs a better understanding of innovation, the more chances that it will adopt the innovation [8]. It also significantly reduces the cost of companies to access a wide variety of computing resources for relatively short amounts of time [14].

The factor relative advantage in this study is defined that organisations used the new technology CC services successfully to achieve businesses objective. To understand the phenomena five questions are inquired in the questionnaire.

Question 1: The integrity and confidentiality of data are preserved under the CC model;10 respondents agree that integrity and confidentiality of data are preserved under CC, while 7 respondents strongly agree on it. Whereas, respondents have zero response on neutral, disagree and strongly disagree with each one respectively.

Question 2: CC improves an organisations operational efficiencies, productivity and enables them to accomplish tasks more quickly;9 respondents agree that $\mathrm{CC}$ improves organisations operational efficiencies and productivity, while 8 respondents strongly agree on it. As concern with neutral, disagree and strongly disagree zero response each one respectively.

Question 3: CC would enhance organisations data storage capacity whenever needed;14 respondents strongly agree that $\mathrm{CC}$ would enhance organisation data storage capacity whenever needed, while only 3 respondents agree on it. As concern with neutral, disagree and strongly disagree zero response each one respectively.

Question 4: The pay-as-you-go model of payment makes $C C$ an attractive solution;9 respondents strongly agree thepay-as-you-go model makes CC attractive solution, while 8 respondents agree on it. Interestingly the same as neutral, disagree and strongly disagree zero response each one respectively.

Question 5: CC enables staff to use the latest versions of technology to improve their performance; 9 respondents agree that $\mathrm{CC}$ enables staff to use the latest versions of the technology, while 8 respondents strongly agree on it. As concern with neutral, disagree and strongly disagree zero response each one respectively.

\begin{tabular}{|l|c|c|c|c|c|}
\hline Questions & $\begin{array}{l}\text { Strongly } \\
\text { Disagree }\end{array}$ & Disagree & Neutral & Agree & $\begin{array}{l}\text { Strongly } \\
\text { Agree }\end{array}$ \\
\hline $\begin{array}{l}\text { The integrity and confidentiality of data is } \\
\text { preserved under the CC model. }\end{array}$ & 0 & 0 & 0 & 10 & 7 \\
\hline $\begin{array}{l}\text { CC improves an organisations operational } \\
\text { efficiencies, productivity and enables to } \\
\text { accomplish tasks more quickly. }\end{array}$ & 0 & 0 & 0 & 9 & 8 \\
\hline $\begin{array}{l}\text { CC would enhance an organisations data } \\
\text { storage capacity whenever needed. }\end{array}$ & 0 & 0 & 0 & 3 & 14 \\
\hline
\end{tabular}


The pay-as-you-go model of payment makes $\mathrm{CC}$ an attractive solution.

$\mathrm{CC}$ enables staff to use the latest versions of technology to improve their performance.

\section{G. Complexity}

Complexity refers to "the degree to which an innovation is perceived as relatively difficult to understand and use" $[22,14,23]$. Therefore, to be more precise, a technology which is difficult to understand, and its use considered to be complex. Though being considered complex technology, it will take too much time and efforts to be learned. On the other hand, if the user also spends too much time to perform its other normal responsibilities as well. With regards to increasing adoption rate, new technology should be user-friendly and easy to use. Generally, sometime new ideas are simple to understand and will be adopted more rapidly, whereas, some innovations that really require the adopter to develop new skills and understandings [24]. In contrast to other innovation characteristics $\mathrm{CC}$ the level of complexity of the system has a negative influence on the adoption of cloud computing: To investigate about the complexity four questions are used to investigate whether complexity influences CC services adoption.

Question 1: Organisations should be concerned with the level of professional skill and capability to evaluate cloud solutions; in this regard, 8 respondents agree and strongly agree with each one

\begin{tabular}{l|l|l|l|}
0 & 0 & 8 & 9 \\
\hline 0 & 0 & 9 & 8 \\
\hline
\end{tabular}

respectively that organisations should be concerned with the level of professional skill. While only 1 respondentneutral on it. Whereaszero respondent disagreesand strongly disagree with each one respectively.

Question 2:Organisations should be concerned about the level of standardisation; 9 respondents agree that organisationsshould be concerned about the level of standardisation, while 7 respondents strongly agree on it. Whereas only 1 respondentneutral on it, zero respondentdisagreeand strongly disagree with each one respectively.

Question 3: Organisations should have a clear plan and funding;10 respondents strongly agree that organisations should have a clear plan and funding, while 7 respondents agree on it. Whereas zero respondentstrongly disagrees, disagree and neutralwith each one respectively.

Question 4:Organisations should understand the business case for cloud adoption; 12 respondents agree that the organisation should understand the business case for cloud adoption, while 5 respondents strongly agree on it. Whereas zero respondent strongly disagrees, disagree and neutral with each one respectively.

\begin{tabular}{|l|r|r|r|r|r|}
\hline Questions & $\begin{array}{l}\text { Strongly } \\
\text { Disagree }\end{array}$ & Disagree & Neutral & Agree & $\begin{array}{l}\text { Strongly } \\
\text { Agree }\end{array}$ \\
\hline $\begin{array}{l}\text { Organisations should be concerned with the level of } \\
\text { professional skill and capability to evaluate cloud } \\
\text { solutions. }\end{array}$ & 0 & & & & \\
\hline $\begin{array}{l}\text { Organisations should be concerned about the level of } \\
\text { standardisation. }\end{array}$ & 0 & 0 & 1 & 8 & \\
\hline Organisations should have a clear plan and funding. & 0 & 0 & & & \\
\hline $\begin{array}{l}\text { Organisations should understand the business case } \\
\text { for cloud adoption. }\end{array}$ & 0 & 0 & 0 & & 7 \\
\hline
\end{tabular}

\section{H. Compatibility}

Refers to compatibility constructs which significantly influence the adoption rate of innovations, "The degree to which an innovation is perceived as consistent with the existing values, past experiences, and needs of potential adopters" $[8,14,23]$. Company's expectations with respect to cloud services adoption are to be compatible, easyto-use and fairly comfortable soon after adoption. Compatibility concern with regards to $\mathrm{CC}$ is recognised as consistent with the existing values, past experience, and particular needs of the companies. In another way, compatibility is concerned with norms and culture of the organization, and especially with respect to technical aspects of the work environment [13].
Therefore, the compatibility with the CC services environment investigated by three questions.

Question 1: Should CC be compatible with organisations norms and culture;10 respondents strongly agree that $\mathrm{CC}$ is compatible with organisations norms and culture, while 6 respondents agree on it. Whereas only one respondent neutral on it and zero respondent disagrees and strongly disagree with each one respectively.

Question 2: Should CC is compatible with all aspects of the organisations work;9 respondents agree that $\mathrm{CC}$ is compatible with all aspects of the organisations work, while 7 respondents strongly agree on it. Whereasonly one respondent neutral on 
it and zero respondentdisagrees and strongly disagree with each one respectively.

Question 3: Cloud should be easily integrated into organisations existing IT Infrastructure;interestingly for this question, 10 respondents agree that cloud should be easily integrated into organisations existing IT Infrastructure, while 5 respondents strongly agree on it. Whereas with respect to strongly disagrees, disagree and neutral zero response on this regard each with this respectively.

\begin{tabular}{|l|r|r|r|r|r|}
\hline Questions & $\begin{array}{l}\text { Strongly } \\
\text { Disagree }\end{array}$ & \multicolumn{1}{|c|}{ Disagree } & Neutral & Agree & $\begin{array}{l}\text { Strongly } \\
\text { Agree }\end{array}$ \\
\hline $\begin{array}{l}\text { Should CC be compatible with } \\
\text { organisations norms and culture. }\end{array}$ & 0 & 0 & 1 & 6 & 10 \\
\hline $\begin{array}{l}\text { Should CC be compatible with all } \\
\text { aspects of the organisations work. }\end{array}$ & 0 & 0 & 1 & 9 & 7 \\
\hline $\begin{array}{l}\text { Cloud should be easily integrated into } \\
\text { an organisations existing IT } \\
\text { Infrastructure. }\end{array}$ & & & & & \\
\hline
\end{tabular}

\section{Security and Privacy}

Refers to CC security and privacy in which CC is perceived as being more secure than other computing paradigms to perform business activities. The CSPs claim that they are able to protect the company's valuable data more securely than the companies itself. Whereas, security is concerned as the security of any type of service, data centres, media, more considerably the privacy and confidentiality of the company's valuable data [25].

As CC comprises numerous technologies including databases, virtualization, resource scheduling, networks, operating systems, memory management, load balancing, concurrency control, and transaction management. Subsequently, security issues for many of these different systems and their respective technologies are applicable to CC [12]. Although the maturity accomplished by the Cloud solutions and the security certifications attain by the main CSPs, but security still stands as the main barrier to adopt $\mathrm{CC}$ services for the critical applications and their sensitive data [26]. Therefore, in contrast, higher levels of security and privacy influence on the adoption of secure $\mathrm{CC}$ database; hence in the context of $\mathrm{CC}$, the security and privacy try to investigate by the six questions:

Question 1: Organisations should ensure that the servers, data centres and data services provided by the CSPs are secure; 10 respondents strongly agree that organisations should ensure that the server, data centres and data services provided by the CSP are secure, while 7 respondents agree on it. Interestingly zero response with regards to neutral, strongly disagree and disagree with each one respectively.

Question 2: Organisations should ensure that the media is used to transmit valuable data to cloud data centres is secure and confidentiality of data is maintained by the CSPs;12 respondents strongly agree that organisations should ensure that the media is used to transmit valuable data to cloud data centres is secure and confidentiality of data is maintained by the CSPs, while 5 respondents agree on it. Interestingly zero response with regards to neutral, strongly disagree and disagree with each one respectively.

Question 3: The Data security and confidentiality of the information is the biggest challenge faced by an organisation adopting any new technology; 12 respondents strongly agree that data security and confidentiality of the information is the biggest challenge faced by an organisation adopting any new technology, while 5 respondents agree on it. Interestingly zero response with regards to neutral, strongly disagree and disagree with each one respectively.

Question 4: A contract agreement between the organisation and the CSP should ensure the safety and reliability of the data; 9 respondents agree that contract agreement between the organisation and the CSP should ensure the safety and reliability of the data, while 8 respondents strongly agree on it. Interestingly zero response with regards to neutral, strongly disagree and disagree with each one respectively.

Question 5: Organisations ensure the CSP is ISO 27001 certified to indeed the data held is encrypted, where data is stored in the cloud and what the backup plan is;interestingly with regard to this question the 15 respondents agree that organisations ensure the CSP is ISO 27001 certified to indeed the data held is encrypted, where data is stored in the cloud and what the backup plan is, while 2 respondents agree on it. Whereas with respect to strongly disagrees, disagree and neutral zero response on this regard each with this respectively. 
Question 6: Organisations should carry out penetration testing to check the security of the CSP and also obtain reports from CSPS on security breaches that might affect the organisations data;9 respondents agree that organisations should carry out penetration testing to check the security of the CSP and also obtain reports from CSPs on security breaches that might affect the organisations data,

\begin{tabular}{|c|c|c|c|c|c|}
\hline Questions & $\begin{array}{l}\text { Strongly } \\
\text { Disagree }\end{array}$ & Disagree & Neutral & Agree & $\begin{array}{l}\text { Strongly } \\
\text { Agree }\end{array}$ \\
\hline $\begin{array}{l}\text { Organisations should ensure that the servers, } \\
\text { data centres and data services provided by } \\
\text { the CSPs are secure. }\end{array}$ & 0 & 0 & 0 & 7 & 10 \\
\hline $\begin{array}{l}\text { Organisations should ensure that the media } \\
\text { is used to transmit valuable data to cloud } \\
\text { data centres is secure and confidentiality of } \\
\text { data is maintained by the CSPs. }\end{array}$ & 0 & 0 & 0 & 5 & 12 \\
\hline $\begin{array}{l}\text { The Data security and confidentiality of the } \\
\text { information is the biggest challenge faced by } \\
\text { an organisation adopting any new } \\
\text { technology. }\end{array}$ & 0 & 0 & 0 & 5 & 12 \\
\hline $\begin{array}{l}\text { A contract agreement between the } \\
\text { organisation and the CSP should ensure the } \\
\text { safety and reliability of the data. }\end{array}$ & 0 & 0 & 0 & 9 & 8 \\
\hline $\begin{array}{l}\text { Organisations ensure the CSP is ISO } 27001 \\
\text { certified to indeed the data held is encrypted, } \\
\text { where data is stored in the cloud and what } \\
\text { the backup plan is. }\end{array}$ & 0 & 0 & 0 & 15 & 2 \\
\hline $\begin{array}{l}\text { Organisations should carry out penetration } \\
\text { testing to check the security of CSP and also } \\
\text { obtain reports from CSPs on security } \\
\text { breaches that might affect the organisations } \\
\text { data. }\end{array}$ & 0 & 0 & 0 & 9 & 8 \\
\hline
\end{tabular}

\section{CostEffectiveness}

Reduction in the total cost has been recognised as one of the main factors that encourage the organizations to adopt $\mathrm{CC}$. The traditional process often involves for most organisations, buying the required technology and tools, getting the consulting services, also paying for installation and license and signing up a maintenance contract for a long period of time [12]. Refers to the costeffectiveness construct of $\mathrm{CC}$ in which decision makers observe the total cost of $\mathrm{CC}$ utilisation lower than other computing paradigms. The CSP's claim that the latest technologies service considerably reduce total IS cost of the companies [11]. Whereas, cost and time saving, increased efficiency, flexibility and scalability of resources, increased collaboration in innovation, quick recovery of data in case of emergency, also the better communication with a client are among key advantages of CC [2]. Whereas the total cost includes fixed cost including initial investment, variable cost is part of the maintenance and upgrade of the systems, and especially the training cost. Therefore, the benefit of utilising low-cost service increases the likelihood of adoption of while 8 respondents strongly agree on it. Whereas with respect to strongly disagrees, disagree and neutral zero response on this regard each with this respectively. secure CC [10]; hence in the context of CC the six questions are used to investigate the cost effects:

Question 1: CC should facilitate organisations to focus on modern IT system projects, which aim to reduce capital investment and improve productivity; 8 respondents strongly agree that $\mathrm{CC}$ should facilitate organisations to focus on modern IT system projects, which aim to reduce capital investment and improve productivity, while 7 respondents agree on it. Whereas only 2 respondent neutral on it and zero respondent disagrees and strongly disagree with each one respectively.

Question 2: CC should provide opportunities for innovation, reduction in IT infrastructure and eliminates the cost of upgrading the software; in this regard, 8 respondents agree and strongly agree with each one respectively that $\mathrm{CC}$ should provide opportunities for innovation, reduction in IT infrastructure and eliminates the cost of upgrading the software. While only 1 respondent neutral on it. Whereas zero respondent disagrees and strongly disagree with each one respectively.

Question 3: CC reduces the cost of system maintenance, IT costs (such as IT personnel) and 
reduction in the total cost of computing resources;9 respondents agree that $\mathrm{CC}$ reduces the cost of system maintenance, IT costs (such as IT personnel) and reduction in the total cost of computing resources, while8 strongly agree on it. Whereas zero respondent neutral, disagree and strongly disagree with each one respectively.
Question 4: Costs of using CC are less than the cost of purchasing and maintaining systems in house; 10 respondents agree that costs of using CC are less than the cost of purchasing and maintaining systems in house, while 7 strongly agree on it. Whereas zero respondent neutral, disagree and strongly disagree with each one respectively.

\begin{tabular}{|c|c|c|c|c|c|}
\hline Questions & $\begin{array}{l}\text { Strongly } \\
\text { Disagree }\end{array}$ & Disagree & Neutral & Agree & Strongly Agree \\
\hline $\begin{array}{l}\text { CC should facilitate organisations to focus on } \\
\text { modern IT system projects, which aim to reduce } \\
\text { capital investment and improve productivity. }\end{array}$ & 0 & 0 & 2 & 7 & 8 \\
\hline $\begin{array}{l}\text { CC should provide opportunities for innovation, } \\
\text { reduction in IT infrastructure and eliminates the cost } \\
\text { of upgrading the software. }\end{array}$ & 0 & 0 & 1 & 8 & 8 \\
\hline $\begin{array}{l}\text { CC reduces the cost of system maintenance, IT costs } \\
\text { (such as IT personnel) and reduction in total cost of } \\
\text { computing resources. }\end{array}$ & 0 & 0 & 0 & 9 & 8 \\
\hline $\begin{array}{l}\text { Costs of using CC are less than the cost of } \\
\text { purchasing and maintaining systems in house. }\end{array}$ & 0 & 0 & 0 & 10 & 7 \\
\hline
\end{tabular}

\section{DISCUSSION ON FINDINGS.}

The primary objective of the study is to analyse different factors affecting $\mathrm{CC}$ adoption in England. The result of the study focuses on the relationship between the key cloud adoptions factors (for instance, Relative Advantage, Complexity, Compatibility, Security and Privacy and CostEffectiveness) against the determination of organisation willing or plan to adopt and using the $\mathrm{CC}$ technology. To achieve the research objective the discussion based on the data collected through the interview on different factors. The research finding will be discussed in relation to the factors and their respective influence on $\mathrm{CC}$ technology in the framework of the organisation.

\section{RESEARCH OBJECTIVES:}

A. Respondents experience will be investigated about the cloud and IT job experience in different organisations sizes and sectors in England. The interview data reflects that a large number of respondents have $5-8$ years such as $70.59 \%$ have cloud experience, whereas low number on $0-5$ years of cloud experience of the respondents are $29.41 \%$. While IT job experience respondents with $11-20$ years of IT experience are $76.47 \%$ quiet encouraging in number and the respondents with0 - 10 years of experience in IT are $23.53 \%$.

The respondents participated in this research are already using different types of CC services, they have sufficient CC services and different types of IT experience, which indicate the reliability of data. The respondents also have practical experience at different levels in the organisations, for instance, executive/middle management and technical staff involvement and different sectors and sizes of organisations, which build confidence on results accuracy and reliability up to certain degrees. The results revealed that respondents have good experience in the cloud and in the IT fields also. Which reflect that they up to certain extent technical understanding of the pros and cons of CC services and IT technology and their response really build confidence for this research.

B. Regarding relative advantage the respondent's responses been collected through five questions about the $\mathrm{CC}$ services. Interestingly mostly respondents are supporting the integrity and confidentiality of data must be preserved, also improves the operational efficiencies, productivity and help to accomplish tasks quickly. About the enhancement of data storage capacity whenever needed, the attraction of the pay-as-you-go payment model and enables staff to use the latest versions of technologies, which help them to improve and empower their performance.

C. Complexity is a relatively difficult domain in CC services, the respondents were investigated through four questions. The overall response was positive in this regards, for instance, professional skill, capacity to evaluate cloud solutions, concern about the level of standardisation, clear plan and funding's and finally understanding about the business case for $\mathrm{CC}$ adoption. The majority of respondents 
supported all the concern regarding the $\mathrm{CC}$, apart from one response each from professional skill, capacity to evaluate cloud solutions, concern about the level of standardisation are neutral, do not shows their interest in this regard.

D. Compatibility of any technology needs more attention because the success of infrastructure it relies on it. In this concern, the respondents are evaluated by three questions. Therefore, organisation norms and culture, compatible with all aspects of the organisations and more significantly easily integrated with existing IT infrastructure are the main concerns. The respondents supported the concern regarding the $\mathrm{CC}$, while one response each from organisation norms and culture, compatible with all aspects of the organisations, do not shows their interest in this regard.

E. Security and privacy in $\mathrm{CC}$ is a very crucial area and need proper attention all the time to secure the working environment, in this regards six questions formulated to deeply analyse. The concern the servers, data centres and data services are secured by CSPs, ensured the means of data transmission are secured and confidentiality of data is maintained by the CSPs, data security and confidentiality of data is the main challenge, ensured the safety and reliability of the data through service level agreement, ensured that CSPs is ISO 27001 certified, data encrypted, geolocation data stored and back plan as well. All the respondents supported that these factors need to address for the use of CC technology, to secure their valuable data, information and their infrastructure ad build confidence. Ensurance of these factors give peace of mind to organisations for the utilisation of $\mathrm{CC}$ technology and enjoy the productivity of technology in their IT infrastructure.

F. Cost factor can be analysed in different aspects as it plays a major role while making a decision to adopt $\mathrm{CC}$ technology. Therefore, cost-effectiveness has been investigated with four questions. In this regards the organisations main aim reduction in investment and improving productivity, elimination in the cost of upgrading the software, reduction in the cost of system maintenance and computing resources and finally saving cost in different aspects by using CC. The majority respondents supported the concerns regarding the $\mathrm{CC}$, while two respondents are neutral in a reduction in investment and improving productivity and one respondent is neutral in elimination in the cost of upgrading the software.

\section{DISCUSSIONS}

Based on the participant's data collected through interview, results reflect a relationship between compatibility, security and privacy and cost effectiveness for their acceptance to adopting secure and cost-effective CC services. Users, especially with IT qualifications, are looks more confident with cloud technology as compared to users without IT qualifications. In this study the adoption of CC services can be influenced by five factors, for instance, relative advantage, complexity, compatibility, security and privacy and cost-effectiveness. Therefore, compatibility, security and privacy and cost-effectiveness are the three main factors that can be considered to encourage or impede the adoption of secure and cost-effective $\mathrm{CC}$ services in England organisations.

Thus, the compatibility of the technology, secure availability of the services and cost-effective plays a major role in the adoption of $\mathrm{CC}$ services. Whereas, assuming that compatibility, secure availability and cost-effectiveness are the critical parameter for the adoption of $\mathrm{CC}$ services to make this technology as a turning point for the organisation for their day to day business activities in England. With regards to ensuring good availability of services, based on the secure, efficient manageable and compatible platform to implement. The security is an extremely significant factor for availability, compatibility factor ensured the smooth running of the business environment and the cost-effectiveness factor is a peace of mind element in this technology.

\section{RECOMMENDATIONS}

For the compatible, secure and cost-effective adoption of different types of CC services, this research recommends that the extensive awareness campaigns to the prospective targeted CC users with respect to cloud data security and privacy. The prospective individuals should be aware of the security and privacy policies and significantly certain measures in place. Additionally, each individual should be educated accordingly on how possibly the security mindful with respect to protecting their valuable sensitive data and information against cyber theft. Furthermore, the $\mathrm{CC}$ users must be very careful of the information 
they provide online, the attention must be focused on the device they use and especially the web sites they visit with regard to prevent their valuable and sensitive information from reaching cybercriminals.

\section{CONCLUSION}

This research analysed with five factors and concluded that CC services have many core benefits for any organisation. The different types and size of the organisations (for instance, Government and private sectors) are looking for this innovative technology for their respective services and presently the $\mathrm{CC}$ can be the right innovative technology solution for them. The study explored the facts based on the five factors from England organisations and revealed on the experience of the staff working within those organisations. This study found overwhelming constructive perception from entirely different sectors of the organisation toward adopting the compatible, secure and cost-effective CC services platform. Also, in the study concern are raised on the security and privacy, complexity and adequate resources.

In this study the possibilities and certain improvements that $\mathrm{CC}$ can deliver to the organisations, such as, accomplish the cutting edge technology at a lower cost. However, there are different types of some concerns and barriers are still related to the adoption of this technology. Whereas, the main concerns about the compatibility, security and privacy issues that the decision makers in some organisations worry about especially in highly sensitive information sectors, for instance, the health care sector, financial sectors.

It can be concluded that compatibility, security and privacy and cost-effectiveness are the major factors that can encourage the adoption of the $\mathrm{CC}$ services. Finally, the research outcome can conclude that the majority of the professionals from different levels in England are keen to utilise the $\mathrm{CC}$ services. Some of the current factors, which are analysed in a different way to investigate multiple aspects that will encourage the adoption procedure were highlighted in this study. Whereas, still more future works will investigate about the adequate resources, complexity, compatibility, secure and privacy and cost-effective adoption process to figure out the impact of these results in a different aspect to help the organisation and built their confidence in cloud technology.

\section{REFERENCES}

[1] Paper: How large are software cost overruns? A review of the 1994 CHAOS report. Authors MagneJørgensen and KjetilMoløkken. Information and Software Technology, 297 $301 . \quad$ (2006). Norway. http://www.umsl.edu/ sauterv/analysis/Standish/standishIST.pdf

[2] Research Article: Challenge of Cloud Computing for SMEs: A Case of Baltic Countries. Authors KarlisKreslins, Darya Novik and TatjanaVasiljeva. IBIMA Publishing Journal of Innovation Management in Small \& Medium Enterprises http://ibimapublishing.com/articles/JIMSME/2018/238581/ Vol. 2018 (2018), Article ID 238581, 10 pages, ISSN : 2166076X DOI: 10.5171/2018.238581. Published date: 19 June 2018. Latvia. https://ibimapublishing.com/articles/JIMSME/2018/238581/2 38581.pdf

[3] Article: Service Level Management (SLM) in Cloud Computing Third party SLM framework. Authors Gianmario Motta, Linlin You, Nicola Sfondrini, Daniele Sacco and Tianyi Ma. January 2013. Italy. https://pdfs.semanticscholar.org/ca8a/53c8c2d5ef5f68e86be9 620bc8f3133ea04a.pdf

[4] Research Paper: Adoption Of Cloud Computing and Services - An Objective Analysis. Author Srinivas R Kondapalli. FUJITSU AMERICA, INC. Address: 1250 East Arques Avenue Sunnyvale, CA 94085-3470, U.S.A. Copyright $\odot$ 2016 Fujitsu America, Inc. All rights reserved. FPC65-7566$01 \quad 04 / 16.020$. https://www.fujitsu.com/us/Images/Adoption\%20of\%20Clou d\%20Computing\%20and\%20Services_whitepaper.pdf

[5] International Journal: Challenges of Cloud Computing Adoption From the TOE Framework Perspective. Authors, Omar Al-Hujran, Enas M. Al-Lozi, Mutaz M. Al-Debei,
Mahmoud Maqableh. International Journal of E-Business Research Volume 14 - Issue 3 • July-September 2018. Jordan.

https://www.researchgate.net/publication/325951656_Challe nges_of_Cloud_Computing_Adoption_From_the_TOE_Fra mework_Perspective

[6] White Paper: Understanding and Supporting Cloud Computing Adoption in Irish Small- and Medium-Sized Enterprises. By Dr Marian Carcary, Dr Eileen Doherty, Gerard Conway, September 2013. http://eprints.maynoothuniversity.ie/4943/1/MC_understandi ng\%20cloud.pdf

[7] Paper: A "cloud lifestyle": The diffusion of cloud computing applications and the effect of demographic and lifestyle clusters. Authors Coursaris, C. K., van Osch, W., \& Sung, J. (2013). Paper presented at the 2013 46th Hawaii International Conference on System Sciences, Hawaii, USA

[8] Conference: Factors Influencing an Organisation's Intention to Adopt Cloud Computing in Saudi Arabia. Author NoufAlkhater, Gary Wills and Robert Walters. School of Electronics and Computer Science University of Southampton Southampton, United Kingdom.2014 IEEE 6th International Conference on Cloud Computing Technology and Science. 978-1-4799-4093-6/14 \$31.00 @ 2014 IEEE DOI 10.1109/CloudCom.2014.95. Pg 1040-1044. UK. https://eprints.soton.ac.uk/372717/1/my\%2520paper.pdf

[9] Journal: A Review On Issues And Challenges Of Cloud Computing. Authors Sangita Das, AnkitaChandrakar and Reshamlal Pradhan. International Journal of Innovations \& Advancement in Computer Science IJIACS ISSN $2347-$ 8616 Volume 4, Issue 1, January 2015. India. http://academicscience.co.in/admin/resources/project/paper/f 201501211421857134.pdf 
[10] Conference: Understanding the Determinants of Cloud Computing Adoption for High Performance Computing. Authors Theo Lynn, Xiaoning Liang, Anna Gourinovitch, John P. Morrison, Grace Fox and PierangeloRosati. Proceedings of the 51st Hawaii International Conference on System Sciences. ISBN: 978-0-9981331-1-9 (CC BY-NCND 4.0). Pg 3894-3903. January 2018. Ireland. https://scholarspace.manoa.hawaii.edu/bitstream/10125/5037 7/1/paper0490.pdf

[11] Journal: The Influence Of Information Security On The Adoption Of Cloud Computing: An Exploratory Analysis. Authors Omondi John Opala, Shawon Rahman and AbdulhameedAlelaiwi. International Journal of Computer Networks \& Communications (IJCNC) Vol.7, No.4, July 2015. USA. http://airccse.org/journal/cnc/7415cnc04.pdf

[12] International Journal: Factors Influencing Cloud Computing Adoption in Saudi Arabia's Private and Public Organizations: A Qualitative Evaluation. Author Mohammed AteeqAlanezi. (IJACSA) International Journal of Advanced Computer Science and Applications, Vol. 9, No. 4, 2018. Saudi Arabia. http://thesai.org/Downloads/Volume9No4/Paper_21-

Factors_Influencing_Cloud_Computing_Adoption_in_Saudi _Arabia.pdf

[13] Article: Factors Influencing Cloud Computing Adoption in the Public Sector: An Empirical Analysis. Authors HasimiSallehudin, RazliCheRazak and Mohammad Ismail. Journal of Entrepreneurship and Business E-ISSN: 22898298 Vol. 3, Issue 1, pp. 30 - 45. June, 2015. Malaysia. https://pdfs.semanticscholar.org/2d82/f6466795f419115a4e0 142d9ef8370509d0f.pdf

[14] Conference: Predicting SMEs willingness to adopt ERP, CRM, SCM \& E-procurement systems. Authors Ben Ramdani and Peter Kawalek. (2008), 16th European Conference on Information Systems. Galway, UK. https://pdfs.semanticscholar.org/4644/167b53e7f4e7789b81ff 34322fb8075ee549.pdf

[15] Journal: Cloud computing: state-of-the-art and research challenges. Authors Zhang, Q., Cheng, L. \&Boutaba, R. (2010). Journal of Internet Services and Applications. [Online]. 1 (1). p.pp. 7-18. Canada. https://link.springer.com/article/10.1007\%2Fs13174-0100007-6

[16] Conference: Digital Signature as a Cloud-based Service. Author WojciechKinastowski. CLOUD COMPUTING 2013 : The Fourth International Conference on Cloud Computing, GRIDs, and Virtualization. Poland. https://www.thinkmind.org/download.php?articleid=cloud_c omputing_2013_3_20_20041

[17] Book: Limitations and challenges in cloud-based applications development. Authors Pramod, N., Muppalla, A. K., \&Srinivasa, K. (2013). In Z. Mahmood \& S. Saeed (Eds.), Software Engineering Frameworks for the Cloud Computing Paradigm (pp. 55-75). London: Springer.

[18] Conceptual Paper: Adoption And Implementation Of Cloud Computing Services: A Railroad Company Case. Authors Dalsang Chung and Sun Gi Chun. Issues in Information Systems Volume 15, Issue II, pp. 276-284, 2014. USA. http://iacis.org/iis/2014/126_iis_2014_276-284.pdf

[19] Journal: Benefits And Challenges Of The Adoption Of Cloud Computing In Business. Authors Colin Ting Si Xue and Felicia Tiong Wee Xin. International Journal on Cloud Computing: Services and Architecture (IJCCSA) Vol. 6, No. 6. December 2016. DOI: 10.5121/ijccsa.2016.6601 1 . Malaysia.

http://aircconline.com/ijccsa/V6N6/6616ijccsa01.pdf
[20] IEEE International Conference:Cloud Computing: Issues and Challenges. Authors Tharam Dillon, Chen Wu and Elizabeth Chang. (2010). In: 2010. 24th IEEE International Conference on Advanced Information Networking and Applications. [Online]. 2010, IEEE, pp. 27-33. Australia. http://ieeexplore.ieee.org/lpdocs/epic03/wrapper.htm?arnumb er $=5474674$

[21] Article: Cloud Computing Adoption in Organisations: Review of Empirical Literature. Authors Haslinda Hassan, MohdHerryMohd Nasir and NorhaizaKhairudin. SHS Web of $\begin{array}{lllll}\text { Conferences } & 34, & 02001 & \text { (2017). DOI: }\end{array}$ 10.1051/shsconf/20173402001. January 2017. Malaysia. https://www.researchgate.net/publication/313740894_Cloud_ Computing_Adoption_in_Organisations_Review_of_Empiric al_Literature

[22] Book: Integrated Series in Information Systems Volume 28, Information Systems Theory, Explaining and Predicting Our Digital Society, Vol. 1, Authors Yogesh K. Dwivedi, L Michael R. Wade and Scott L. Schneberger, () Springer Science+Business Media, LLC 2012, ISSN 1571-0270 ISBN 978-1-4419-6107-5 e-ISBN 978-1-4419-6108-2 DOI 10.1007/978-1-4419-6108-2.

https://www.researchgate.net/profile/Nripendra_Rana/publica tion/226493128_A_Bibliometric_Analysis_of_Articles_Citin g_the_Unified_Theory_of_Acceptance_and_Use_of_Techno logy/links/542a9c300cf277d58e874b6e.pdf

[23] International Journal: A Review on Cloud Computing Security. Authors Marry Teo, HairulnizamMahdin, Lee JiaHwee, Haezel Ann Dicken, Tay Xin Hui, TengMee Ling and MohdSanusiAzmi. International Journal On Informatics Visualization. VOL 2 (2018) NO 4 - 2. e-ISSN : 2549-9904. ISSN : 2549-9610. 2018. Malaysia. https://www.researchgate.net/publication/327576415_A_Rev iew_on_Cloud_Computing_Security

[24] Book: Diffusion Of Innovations. Author Everett M. Rogers. Third Edition, 1983. ISBN 0-02-926650-5. https://teddykw2.files. wordpress.com/2012/07/everett-mrogers-diffusion-of-innovations.pdf

[25] Journal:. Factors Affecting Cloud Computing Adoption in a Developing Country - Ghana: Using Extended Unified Theory of Acceptance and Use Of Technology (UTAUT2) Model Authors Rebecca AdwoaAmponsah, Joseph KobinaPanford and James Ben Hayfron-Acquah. International Research Journal of Engineering and Technology (IRJET) e-ISSN: 2395 -0056, p-ISSN: 23950072, Volume: 03 Issue: 11,| Nov -2016. Ghana. Pp. 59-76. https://www.irjet.net/archives/V3/i11/IRJET-V3I1109.pdf

[26] Survey Paper: Public Cloud Adoption in Multinational Companies - A survey. Author Nicola Sfondrini. Conference: IEEE INTERNATIONAL CONFERENCE ON SERVICES COMPUTING At: San Francisco. July 2018. Italy. https://www.researchgate.net/publication/326272130_

[27] Journal: A Survey Based Investigation for Cloud Computing Adoption Internationally. Authors Raja Muhammad Ubaid Ullah, Dr.Kevan A. Buckley,Dr. Mary Garvey andDr. Jun Li. International Journal of Computer Trends and Technology (IJCTT) - Volume 67 Issue 4 - April 2019. ISSN: 2231-2803 United Kingdom. http://www.ijcttjournal.org Page 106

[28] Journal: A Systematic Literature Review of Factors Affecting Cloud Computing Adoption Internationally. Authors Raja M. Ubaid Ullah, Dr.Kevan A. Buckley,Dr. Mary Garvey andDr. Jun Li. International Journal of Computer Trends and Technology (IJCTT) - Volume 67 Issue 3 - March 2019. ISSN: $2231-2803$ United Kingdom. http://www.ijcttjournal.org Page 41 